\title{
High-density Lipoprotein Cholesterol as a Risk Factor of Health-Related Quality of Life in 50-70-Year-Old Community- Dwelling Women
}

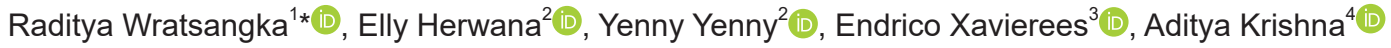 \\ ${ }^{1}$ Department of Obstetrics and Gynecology, Faculty of Medicine, Universitas Trisakti, West Jakarta, Indonesia; ${ }^{2}$ Department \\ of Pharmacology and Therapeutics, Faculty of Medicine, Universitas Trisakti, West Jakarta, Indonesia; ${ }^{3}$ Department of \\ Biochemistry, Faculty of Medicine, Universitas Trisakti, West Jakarta, Indonesia; ${ }^{4}$ Department of Physiology, Faculty of \\ Medicine, Universitas Trisakti, West Jakarta, Indonesia
}

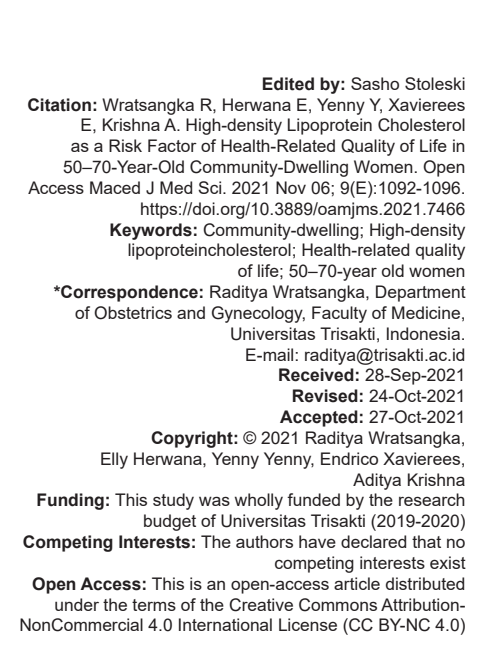

\section{Abstract}

BACKGROUND: The prevalence of dyslipidemia, a risk factor of cardiovascular disease, is at present sufficiently high, particularly in the elderly. Health-related quality of life (HRQoL) is also an important outcome in the treatment of dyslipidemia, which is currently more targeted at lowering the low-density lipoprotein cholesterol (LDL-C) concentration.

AIM: The aim of this study was to determine the relationship between the high-density lipoprotein cholesterol (HDL-C) concentration and HRQoL in community-dwelling women aged 50-70 years.

METHODS: A cross-sectional study involving 137 women aged 50-70 years who underwent blood sampling for determining the concentrations of hemoglobin, total cholesterol (TC), LDL-C, and HDL-C. A questionnaire was given to all subjects regarding data on age, menopausal status, level of education, and also another questionnaire of SF-36 for evaluation HRQoL. Bivariate and multivariate logistic regression analysis was used to identify risk factors associated with HRQoL.

RESULTS: In bivariate logistic regression analysis, age, menopausal status, education level, anemia, TC, and LDL-C were found to have non-statistically significant association with HRQoL, but HDL-C was significantly associated with $\mathrm{HRQoL}$ (odds ratio $=0.44 ; 95 \%$ Confidence interval $[\mathrm{Cl}]=0.20-0.97 ; \mathrm{p}=0.042$ ). In multivariate analysis, menopausal status and education level have a non-statistically significant association with HRQoL, but those normal level of HDL cholesterol was found 0.18 times less likely to be associated with poor HRQL (Adjusted odds ratio $0.18 ; 95 \% \mathrm{Cl}=0.03-0.91 ; \mathrm{p}=0.038$ )

CONCLUSION: This study showed that HDL-C levels were risk factors of HRQoL in women 50-70 years of age.

\section{Introduction}

The health-related quality of life (HRQoL) is currently an important outcome that is reported by patients during or after treatment of a disorder, in addition to increasing the life expectancy in such chronic conditions as hypertension, cardiac failure, and diabetes [1]. Various health problems may occur with increasing age of an individual, and the life style changes that occur in old age may result in dyslipidemia. The prevalence of dyslipidemia in subjects aged $>60$ years is around $56.8 \%$, with high total cholesterol (TC), high low-density lipoprotein cholesterol (LDL-C), low highdensity lipoprotein cholesterol (HDL-C), and high triglycerides prevalence rates of $8.4 \%, 13.9 \%, 23.1 \%$, and $11.4 \%$, respectively [2].

Dyslipidemia, especially of LDL-C, has a causal relationship with atherosclerotic cardiovascular disease according to genetic, observational, and clinical outcome studies [3], [4]. Several epidemiological studies have also demonstrated that a low plasma HDL-C concentration is a risk factor of cardiovascular disease. The HDL-C concentration may predict cardiovascular incidence, even in patients who have been treated with statins, but clinical studies on the relationship of increased HDL-C concentration with cardiovascular protection are not convincing [5], [6].

The results of the previous studies demonstrate a still inconsistent relationship between HDL-C concentration and quality of life. Studies conducted on a group of male and female subjects aged $50-79$ years showed that a decrease in LDL-C concentration and an increase in HDL-C concentration are associated with increased HRQoL [7]. However, inconsistent results were found in a study involving subjects aged 100 years and over, showing that HDL-C concentration is not significantly associated with quality of life [8]. Therefore, a study was performed to determine plasma HDL-C concentration as a risk factor of HRQoL in 
community-dwelling women aged between 50 and 70 years.

\section{Material and Methods}

\section{Study design and participants}

This was a cross-sectional study conducted in five villages (kelurahan) of Mampang Prapatan Sub-district, South Jakarta, from March to July 2020. The sample size was calculated based on a correlation between HDL-C concentration and HRQoL of 0.34 (data from a preliminary study using 40 women aged $50-70$ years), $\sigma=0.05$ and $\beta=0.1$, from which a sample size of 113 subjects was found. With an anticipated study drop-out rate of $15 \%$, the optimal sample size was found to be 130 . The inclusion criteria were women aged between 50 and 70 years, agreeing to undergo a complete blood examination, capable of good communication, and agreeing to sign informed consent. Women with neurological disorders (stroke, epilepsy, Parkinson's disease, and dementia), and psychiatric disorders (major depression and psychosis) were excluded from the study. Selection of the study subjects was by consecutive non-random sampling.

Informed consent was signed by the subjects after having received oral and written information on the general outlines of the study. For the protocol of this study, ethical clearance was obtained from the Research Ethics Commission, Faculty of Medicine, Universitas Trisakti under no. 160/KER/FK/II/2020.

\section{Questionnaire}

To all subjects, a questionnaire was given regarding data on socio-demographic characteristics comprising age, menopausal status, and level of education. The variable of age, menopause status, and education level was each categorized into two groups: (1) Age: (a) <60 years and (b) $\geq 60$ years; (2) menopause status: (a) Premenopause and (b) postmenopause; and (3) education level: (a) Low and (b) moderate/high.

\section{HRQoL}

Evaluation of the HRQoL was performed using the SF-36 questionnaire consisting of 36 questions or statements. The filling-in of the questionnaire was done with the assistance of the enumerators in interviews with the subjects. There was also an evaluation of the physical component summary (PCS) with four subcomponents (physical functioning, physical limitations, bodily pain, and general health); and a mental component summary (MCS) with four subcomponents (vitality, social functioning, emotional limitations, and mental health). The quality of life (HRQoL) of the subjects was considered to be good if the SF-36 score was above the median value, and to be poor if the score was under the median value for SF-36 total score, SF-36 PCS, and SF-36 MCS as well as each of the subcomponents [9], [10], [11].

\section{Laboratory analysis}

The subjects were required to fast for $10-12 \mathrm{~h}$ from 20:00 $\mathrm{h}$ of the preceding night. On the following day, $14 \mathrm{~mL}$ of venous blood was drawn from the right cubital vein of each of the subjects. The hemoglobin $(\mathrm{Hb})$ concentration was determined by the cyanide-free sodium lauryl sulfate $\mathrm{Hb}$ detection method using an automated hematological analyzer (type KX-21N, Sysmex, Kobe, Japan). TC and triglyceride concentrations were determined by means of an enzymatic-colorimetric method, while measurement of LDL-C and HDL-C concentrations was by means of the homogenous enzymatic-colorimetric method using the Cobas 311 instrument (Roche Products Ltd, Basel, Switzerland). These variables of laboratory results were each also categorized into two groups: (1) $\mathrm{Hb}$ concentration (g/dL): (a) Normal: $\geq 12$ and (b) low (anemia): <12; (2) TC (mg/dL): (a) Normal: <200 and (b) high: $\geq 200$; (3) LDL-C concentration (mg/dL): (a) Normal: <100 and (b) high $\geq 100$; and (4) HDL-C concentration (mg/dL): (a) Normal: $\geq 40$ and (b) low: $<40$.

\section{Quality control}

All the enumerators were trained on interview technique. The questionnaire was collected on the spot after completion and uniformly numbered in the order of site and recall questionnaire. The laboratory examination was performed by laboratory technicians (who were blinded as to the identity of the subjects to whom the blood samples belonged) at the Prodia Clinical Laboratory-Jakarta that had obtained the SNI certification ISO 15189:2012 as a medical laboratory with regard to quality requirements and competence. The data were checked to avoid inconsistency.

\section{Statistical analysis}

The SPSS version 25 was used for data processing. Descriptive analysis was presented as frequency for categorical data. Bivariate logistic regression analysis was used to find associations between the independent variables and the HRQoL. All the variables showing a significant association in a bivariate analysis at $p<0.25$ were entered into a multivariate logistic regression model to determine risk factors associated with the HRQoL. $p<0.05$ was considered statistically significant. 


\section{Results}

\section{Age and clinical characteristics}

The number of subjects aged $<60$ years and $\geq 60$ years is almost evenly matched, and the majority of the subjects were already in menopause $(94.2 \%)$, had a low level of education (64.9\%). A total of $24(17.5 \%)$ subjects had a low $\mathrm{Hb}$ concentration (anemia); 82 (55.9\%) subjects had a high TC, 119 (86.9\%) subjects had a high LDL-C, and $11(8 \%)$ subjects had a low HDL-C. The number of subjects with poor and good HRQoL is almost balanced, both for total HRQoL, HRQoL PCS, and MCS (Table 1).

Table 1: Distribution of subject based on socio-demographic factor, laboratory findings, and HRQoL $(n=137)$

\begin{tabular}{ll}
\hline Variables & $\mathrm{n}(\%)$ \\
\hline Age (years) & $70(51.1)$ \\
$-\quad<60$ & $67(48.9)$ \\
$\quad$ - $\geq 60$ & \\
Menopause status & $8(5.8)$ \\
$\quad$ - Premenopause & $129(94.2)$ \\
- Postmenopause & \\
Education level & $89(64.9)$ \\
$\quad$ - Low & $48(35.1)$ \\
- Moderate/High & \\
Anemia status & $113(82.5)$ \\
- No & $24(17.5)$ \\
- Yes & \\
Total cholesterol & $55(40.1)$ \\
- Normal & $82(55.9)$ \\
- High & $18(13.1)$ \\
LDL cholesterol & $119(86.9)$ \\
- Normal & $126(92.0)$ \\
- High & $11(8.0)$ \\
HDL cholesterol & \\
- Normal & $69(50.4)$ \\
- Low & $68(49.6)$ \\
HRQoL (total) & \\
- Poor & $67(48.9)$ \\
- Good & $70(51.1)$ \\
HRQoL - Physical Component & $68(49.6)$ \\
- Poor & $69(50.4)$ \\
- Good &
\end{tabular}

HRQoL: Health-related quality of life, HDL. High-density lipoprotein, LDL: Low-density lipoprotein

\section{Risk factors associated with HRQoL}

Age and several risk factors associated with HRQoL were explored using bivariate logistic regression analysis and subsequent multivariate logistic regression analyses. In bivariate logistic regression analysis, age, menopausal status, education level, anemia, TC, and LDL cholesterol were found to have non-statistically significant association with HRQoL (Table 2). However, HDL cholesterol was significantly associated with HRQoL (odds ratio $=0.44 ; 95 \%$ Confidence interval $[\mathrm{Cl}]=0.20-0.97 ; \mathrm{p}=0.042$ ) (Table 2). Normal HDL cholesterol level was found 0.44 times less likely to be associated with poor HRQoL.
Table 2: Bivariate logistic regression between risk factors and HRQoL in women $50-70$ years of age

\begin{tabular}{|c|c|c|c|}
\hline Risk factor & OR & $95 \% \mathrm{Cl}$ & $\mathrm{p}$ \\
\hline \multicolumn{4}{|l|}{ Age (years) } \\
\hline$\cdot<60$ & 1,37 & $0.70-2.76$ & 0.349 \\
\hline$\cdot \geq 60$ & 1 & & \\
\hline \multicolumn{4}{|l|}{ Menopausal status } \\
\hline - Premenopause & 0.12 & $0.01-1.01$ & 0.055 \\
\hline - Postmenopause & 1 & & \\
\hline \multicolumn{4}{|l|}{ Education level } \\
\hline - Low & 0.51 & $0.25-1.04$ & 0.065 \\
\hline - Moderate/High & 1 & & \\
\hline \multicolumn{4}{|l|}{ Anemia status } \\
\hline - No & 0.65 & $0.26-1.59$ & 0.350 \\
\hline •Yes & 1 & & \\
\hline \multicolumn{4}{|l|}{ Total cholesterol } \\
\hline - Normal & 0.96 & $0.48-1.91$ & 0.917 \\
\hline • High & 1 & & \\
\hline \multicolumn{4}{|l|}{ LDL-cholesterol } \\
\hline • Normal & 0.78 & $0.29-2.19$ & 0.637 \\
\hline • High & 1 & & \\
\hline \multicolumn{4}{|l|}{ HDL-cholesterol } \\
\hline • Normal & 0.44 & $0.20-0.97$ & 0.042 \\
\hline - Low & 1 & & \\
\hline
\end{tabular}

In multivariate analysis, menopausal status and education level have not a statistically significant association with HRQoL (Table 3). Those normal level of HDL cholesterol was found 0.18 times less likely to be associated with poor HRQoL (Adjusted odds ratio $=0.18 ; 95 \% \mathrm{Cl}=0.03-0.91 ; \mathrm{p}=0.038)$ (Table 3$)$. It can be concluded that HDL-C levels were a risk factors of HRQoL.

\section{Discussion}

In the present study, we found that the majority of subjects were in postmenopausal. However, menopausal status was not a risk factor of HRQoL. Moreover, this result was in-line with a population-based survey based on 1140 Greek middle-age women found no effect of menopause on the HRQOL [12]. Another study showed different results compared to our study, women experiencing menopause may have impaired HRQOL [13]. Menopause is also the stage of life that is marked by changes in the role of the menopausal woman, such as the cessation of child rearing and child care, or even the prospect of her being abandoned by the children. Although the biological impact of menopause (such as bone loss) is known with regard to its characteristics, the impact of menopause on the functioning and welfare of women (HRQoL) is still unclear [14], [15]. From the results of observations spanning a period of 5 years, Hess et al. [16] found that menopause had a negative impact on several subcomponents of HRQoL, apart from the symptoms of menopause; even the quality of life of the postmenopausal women did not improve after the symptoms of menopause had disappeared. 
Table 3: Multiple logistic regression between risk factors and HRQoL in women $\mathbf{5 0 - 7 0}$ years of age

\begin{tabular}{llll}
\hline Risk factor & AOR & $95 \% \mathrm{Cl}$ & $\mathrm{p}$ \\
\hline $\begin{array}{l}\text { Menopausal status } \\
\text { • Premenopause } \\
\text { - Postmenopause }\end{array}$ & 0.15 & $0.01-1.39$ & 0.091 \\
$\begin{array}{l}\text { Education level } \\
\quad \text { Low }\end{array}$ & 1 & & \\
$\quad$ - Moderate/High & 0.53 & $0.25-1.11$ & 0.094 \\
HDL cholesterol & 1 & & \\
$\quad$ - Normal & 0.18 & $0.03-0.91$ & 0.038 \\
$\quad$ L Low & 1 & & \\
\hline $\begin{array}{l}\text { AOR: Adjusted odds ratio, Cl: confidence interval, HDL: High-density lipoprotein, LDL: Low-density } \\
\text { lipoprotein }\end{array}$ &
\end{tabular}

Subjects with anemia had a lower quality of life (HRQoL) as compared to subjects with normal $\mathrm{Hb}$ concentration (without anemia), but not statistically significant. The impact of anemia on HRQoL has been studied in patients from a number of different populations, and most studies found a relationship between HRQoL and anemia in elderly individuals, which on the subscale level was particularly associated with physical health. Various models of multivariate analysis have concluded that anemia is an independent risk factor of decreased HRQoL in the elderly group. In South Korea, data from the Korean National Health and Nutrition Examination Survey, that used the EQ-5D questionnaire, showed that the overall incidence of anemia in individuals aged 10 years and above was around $8.2 \%$ in 2005-2015 [17].

In this study, it was found that LDL-C was not a risk factor of HRQoL. Dyslipidemia, especially of LDL-C, has a causal relationship with atherosclerotic cardiovascular disease according to genetic, observational, and clinical outcome studies. A number of study results also showed that dyslipidemia impacts on quality of life (QoL), in that patients with dyslipidemia have a low HRQoL when compared with patients without dyslipidemia [4], [5]. In the multivariate logistic regression on $\mathrm{HRQOL}$ involving various risk factors of HRQoL (menopausal status, educational status, and HDL-C), it may be observed that the group of subjects with low HDL-C had a significantly lower quality of life in comparison with the group of subjects with normal HDL-C concentration. From the results of this study, it is also apparent that a low HDL-C concentration was a risk factor of HRQoL. The previous study results showed a still inconsistent relationship between HDL cholesterol concentration and quality of life. The Chinese Hypertension Intervention Efficacy randomized controlled trial conducted on a group of 13,542 men and women aged 50-79 years showed that decreased LDL-C concentration and increased HDL-C concentration were associated with increased HRQoL [14]. The inconsistent results found in a study involving subjects aged 100 years and over showed that HDL-C concentration was not significantly associated with quality of life [8]. Among the oldest elderly (100 years or over), it was found that increased lipid profile was not a risk factor for health and longevity, but in contrast became a protective factor, which differs from traditional reasoning about the impact of blood lipids on health [18], [19].
There is strong evidence for the relationship between high LDL-C concentration and cardiovascular events based on studies of clinical outcomes [20], [21], such that LDL-C constitutes the main target in the management of dyslipidemia. A number of epidemiological studies have also demonstrated that low plasma HDL-C concentration is a risk factor of cardiovascular disease. Similarly, several large-scale randomized clinical trials have proven that administration of $\mathrm{HDL}-\mathrm{C}$-increasing medications to patients with low HDL-C and high triglyceride concentrations may yield beneficial clinical effects. However, up to now the causal relationship between HDL-C concentration and cardiovascular disease cannot be explained. HDL-C may predict cardiovascular events even in patients on statin treatment, but clinical studies on the relationship between increased HDL-C concentration and cardiovascular protection are not convincing [8], [22]. HDL-C is at present used for estimating cardiovascular risk and is not a therapeutic target because the clinical studies are not convincing, even in high-risk patients with the LDL-C concentration meeting the therapeutic target. An HDL-C concentration of $>40 \mathrm{mg} / \mathrm{dL}$ in males and $>50 \mathrm{mg} / \mathrm{dL}$ in women only indicates a lower level of risk.

\section{Limitation}

This observational study with cross-sectional approach cannot prove a causal relationship between HDL-C concentration and HRQoL. Data collected through interview of study participants were subjected to recall bias, particularly in questions related to past events.

\section{Conclusions and Recommendation}

This study demonstrated that HDL-C concentrations were significantly a risk factor of $\mathrm{HRQ} \mathrm{OL}$ in women aged 50-70-years. The effect of lipid profile on health status needs to be considered and further verified in women aged $50-70$ years. As a follow-up to this study, there is a need for conducting a study with a better design, such as a cohort study, that can determine a cause-and-effect relationship between HDL-C concentration and quality of life in women aged $50-70$ years.

\section{Acknowledgments}

We are grateful to Head, Staff, and health cadres from the Mampang Prapatan Sub-district 
Puskesmas, South Jakarta, for the research area and supporting data facility. We are indebted to all respondents who participated in this study.

\section{References}

1. Martino G, Catalano A, Bellone F, Langher V, Lasco C, Penna A et al. Quality of life in postmenopausal women: Which role for Vitamin D? Mediterr J Clin Psychol. 2018;6:1-14. https://doi. org/10.6092/2282-1619/2018.6.1875

2. Lin HQ, Wu JY, Chen ML, Chen FQ, Liao YJ, Wu YT, et al Prevalence of dyslipidemia and prediction of 10-year CVD risk among older adults living in southeast coastal regions in China: A cross-sectional study. Clin Interv Aging. 2019;14:1119-29. https://doi.org/10.2147/CIA.S207665

PMid:31354254

3. Gidding SS, Allen NB. Cholesterol and atherosclerotic cardiovascular disease: A lifelong problem. J Am Heart Assoc. 2019;8(11):e012924. https://doi.org/10.1161/JAHA.119.01292 PMid:31137996

4. Park H. The impact of dyslipidemia on the health-related quality of life of Korean females aged 50 years and older. Iran J Public Health. 2019;48(3):556-8. https://doi.org/10.18502/ijph. v48i3.903

PMid:31223587

5. Ko DT, Alter DA, Guo H, Koh M, Lau G, Austin PC, et al. Highdensity lipoprotein cholesterol and cause-specific mortality in individuals without previous cardiovascular conditions: The CANHEART study. J Am Coll Cardiol. 2016;68(19):2073-83. https://doi.org/10.1016/j.jacc.2016.08.038

PMid:27810046

6. Li YH, Tseng WK, Yin WH, Lin FJ, Wu YW, Hsieh IC, et al Prognostic effect of high-density lipoprotein cholesterol level in patients with atherosclerotic cardiovascular disease under statin treatment. Sci Rep. 2020;10(1):21835. https://doi.org/10.1038/ s41598-020-78828-8

PMid:33318590

7. Yan R, Gu HQ, Wang W, Ma L, Li W. Health-related quality of life in blood pressure control and blood lipid-lowering therapies: Results from the CHIEF randomized controlled trial. Hypertens Res. 2019;42(10):1561-71. https://doi.org/10.1038/ s41440-019-0281-z

PMid:31197264

8. Wang S, Yang S, Jia W, Cao W, Han K, Liu M, et al. Relationships of lipids profile with health-related quality of life in Chinese centenarians. J Nutr Heal Aging. 2020;24:404-11. https://doi. org./10.1007/s12603-020-1340-5

PMid:32242208

9. Karimi M, Brazier J. Health, health-related quality of life, and quality of life: What is the difference? Pharmacoeconomics. 2016;34(7):645-9. https://doi.org/10.1007/s40273-016-0389-9 PMid:26892973

10. Lins L, Carvalho FM. SF-36 total score as a single measure of health-related quality of life: scoping review. SAGE Open Med. 2016;4:205031211667172. https://doi. org/10.1177/2050312116671725

\section{PMid:27757230}

11. Jörling $M$, Rutzner $S$, Hecht $M$, Fietkau $R$, Distel LV. Deterioration of health-related quality of life scores under treatment predicts longer survival. Biomed Res Int. 2020;2020:3565238.

12. Giannouli P, Zervas I, Armeni E, Koundi K, Spyropoulou A, Alexandrou A, et al. Determinants of quality of life in Greek middleage women: A population survey. Maturitas. 2012;71(2):154-61. https://doi.org/10.1016/j.maturitas. 2011.11.013

PMid:22177978

13. Poomalar GK, Arounassalame B. The quality of life during and after menopause among rural women. J Clin Diagnostic Res. 2013;7(1):135-9. https://doi.org/10.7860/JCDR/2012/4910.2688 PMid:23450244

14. Whiteley J, Dibonaventura MD, Wagner JS, Alvir J, Shah S. The impact of menopausal symptoms on quality of life, productivity, and economic outcomes. J Womens Health. 2013;22:983-90. https://doi.org/10.1089/jwh.2012.3719

PMid:24083674

15. Moilanen JM, Aalto AM, Raitanen J, Hemminki E, Aro AR, Luoto R. Physical activity and change in quality of life during menopause -an 8-year follow-up study. Health Qual Life Outcomes. 2012;10:1-7. https://doi.org/10.1186/1477-7525-10-8

16. Hess R, Thurston RC, Hays RD, Chang CC, Dillon SN, Ness RB, et al. The impact of menopause on health-related quality of life: Results from the STRIDE longitudinal study. Qual Life Res. 2012;21(3):535-44. https://10.1007/s11136-011-9959-7 PMid:21755412

17. Kim YJ, Han KD, Cho KH, Kim YH, Park YG. Anemia and healthrelated quality of life in South Korea: Data from the Korean national health and nutrition examination survey 2008-2016. BMC Public Health. 2019;19(1):735. https://doi.org/10.1186/ s12889-019-6930-y

PMid:31196013

18. Ravnskov U, Diamond DM, Hama R, Hamazaki T, Hammarskjöld B, Hynes $\mathrm{N}$, et al. Lack of an association or an inverse association between low-density-lipoprotein cholesterol and mortality in the elderly: A systematic review. BMJ Open. 2016;6(6):e010401. https://doi.org/10.1136/ bmjopen-2015-010401 PMid:27292972

19. Takata Y, Ansai T, Soh I, Awano S, Nakamichi I, Akifusa S, et al Serum total cholesterol concentration and 10-year mortality in an 85-year-old population. Clin Interv Aging. 2014;9:293-300. https://doi.org/10.2147/CIA.S53754 PMid:24611005

20. Baigent C, Blackwell L, Emberson J, Holland LE, Reith C, Bhala N et al. Efficacy and safety of more intensive lowering of LDL cholesterol: A meta-analysis of data from 170000 participants in 26 randomised trials. Lancet. 2010;376(9753):1670-81. https:// doi.org/10.1016/S0140-6736(10)61350-5 PMid:21067804

21. Penson PE, Pirro M, Banach M. LDL-C: Lower is better for longer even at low risk. BMC Med. 2020;18:1-6. https://doi. org/10.1186/s12916-020-01792-7

22. Voight BF, Peloso GM, Orho-Melander M, Frikke-Schmidt R, Barbalic M, Jensen MK, et al. Plasma HDL cholesterol and risk of myocardial infarction: A mendelian randomisation study. Lancet. 2012;380(9841):572-80. https://doi.org/10.1016/ S0140-6736(12)60312-2

PMid:22607825 